\title{
Téoros
}

Revue de recherche en tourisme

\section{Le tourisme de croisière}

\section{Alain A. Grenier}

Volume 27, numéro 2, été 2008

Les grands équipements touristiques

URI : https://id.erudit.org/iderudit/1070796ar

DOI : https://doi.org/10.7202/1070796ar

Aller au sommaire du numéro

Éditeur(s)

Université du Québec à Montréal

ISSN

0712-8657 (imprimé)

1923-2705 (numérique)

Découvrir la revue

Citer cet article

Grenier, A. A. (2008). Le tourisme de croisière. Téoros, 27(2), 36-48.

https://doi.org/10.7202/1070796ar d'utilisation que vous pouvez consulter en ligne.

https://apropos.erudit.org/fr/usagers/politique-dutilisation/ 


\section{Le tourisme de croisière}

\section{Alain A. Grenier}

Chaque année, environ 16 millions de personnes participent à l'une des 30000 croisières (fluviales ou océaniques) offertes dans quelques 2000 destinations dans le monde. De ce nombre, 9,6 millions de passagers participent à une croisière océanique (OMT, 2003 : 27). Une flotte de plus de 339 navires, pouvant accommoder de 50 à 4000 passagers à la fois, répond ainsi à la demande (Ward, 2007 : 14, 18 ; Ebersold, 2004). La croissance annuelle moyenne de 7,6 \% du nombre de croisiéristes sur le marché nord-américain (OMT, 2003 : 28) se traduit par une augmentation du nombre de navires, mais aussi des ports de mer et des destinations visitées. À la fin de la première décennie du XXle siècle, la demande en Amérique du Nord et en Europe dépassera les 13 millions de passagers (OMT, 2003 : 27). Quoique traditionnellement orientée vers le marché américain, l'industrie de la croisière se déploie de plus en plus en Europe, mais aussi en Amérique du Sud, en Asie et vers des marchés hyper spécialisés comme les régions polaires (Antarctique en tête). En fait, l'industrie ne connaît de limites que celles que lui imposent ses infrastructures, en mer (les navires, leur nombre et leur capacité de charge) et au sol (installations portuaires et aéroportuaires et autres services locaux - attractions et restauration).

Le navire de croisière fascine. Pas surprenant, ces complexes touristiques constituent les plus grandes infrastructures mobiles de fabrication humaine (ill. 1). Symboles du perfectionnement de l'ingénierie et du besoin humain de conquête au-delà des continents, ils marient

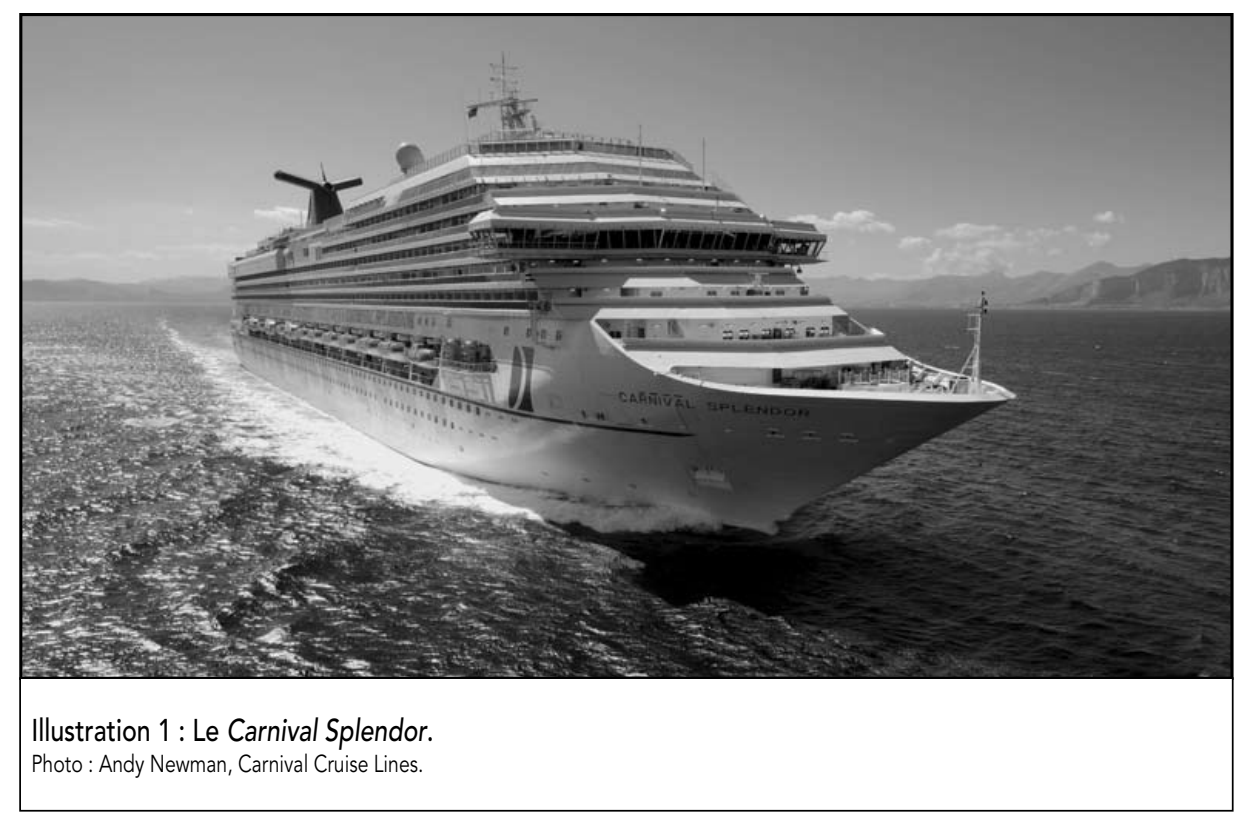

aujourd'hui plus que jamais la suprématie technologique et le goût des loisirs et du luxe. Jadis mandatés pour les grandes traversées intercontinentales, les paquebots (longtemps les seuls moyens de franchir les océans) ont failli ne pas survivre à la commercialisation du transport aérien à la fin des années 1950. Réorientés pour se consacrer aux voyages de plaisir, les navires de croisière ont depuis conquis tous les océans et toutes les mers du monde, de la Méditerranée à la Caraïbe ; du pôle Nord aux côtes antarctiques. En fait, le secteur du tourisme de croisière enregistre la plus forte croissance de l'industrie touristique mondiale.

À partir d'une revue de littérature ainsi que des observations-participantes de l'auteur, cet article offre un tour d'horizon de l'évolution de l'industrie des croisières, y compris de ses tendances et de ses défis.

\section{La croisière : un concept}

Avant d'être une forme de vacances, la croisière est d'abord et avant tout un concept qui, comme le montre l'illustration 2, entremêle tourisme et loisirs, voyage (déplacement) et un mode de transport (Lois et al., 2004 : 94). Le concept naît de la rencontre de préoccupations quant au type de transport, au type d'élément transporté (on distinguera le transport de marchandises et celui de passagers), ainsi que du ou des buts recherchés (on distinguera entre les navigations commerciale, civile et militaire; dans le secteur de la navigation civile, on distinguera entre l'utilisation d'un navire dans le but de surmonter un obstacle géographique - la traverse d'un plan d'eau, et celui d'une expérience nautique à des fins ludiques - la croisière).

Dans le cas des séjours transocéaniques (la traverse), le passager utilisait jadis le navire pour se déplacer entre deux points séparés 


\section{Illustration 2}

Structure et relations de marché du tourisme de croisière

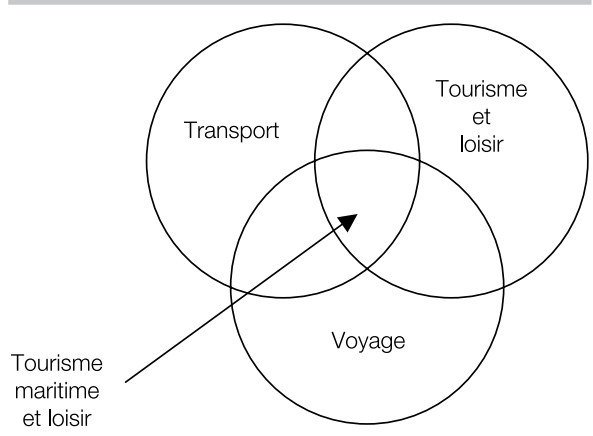

Source : Lois et al. (2004 : 93).

par des océans (l'Europe et l'Amérique, par exemple). On retrouvait de telles liaisons sur tous les grands océans (Atlantique, Pacifique et Indien) ainsi qu'entre l'Europe et l'Orient via le Canal de Suez. Ces traversées permettaient le transport du cargo, mais aussi des passagers, des migrants, des travailleurs et, plus rarement, des voyageurs. Le paquebot est ainsi la continuation du chemin de fer, permettant la liaison de deux destinations par la voie des mers. L'arrivée de l'aviation civile, et l'accélération de la mobilité qu'elle engendre, rend le paquebot futile. Sans raison d'être, il se réinventera, s'attardant au divertissement des passagers, non plus entre deux points, mais en multipliant les escales de découvertes dans des destinations exotiques. Le concept qui en résulte transforme le navire en destination de vacances : c'est la naissance de la croisière.

Pour des fins statistiques, certaines contraintes sont parfois établies pour circonscrire le phénomène de la croisière, comme la taille du navire, le type de plan d'eau utilisé (lac, rivière, fleuve, mer ou océan) ou encore une durée déterminée du passage à bord. Pour les fins de cet article, la croisière est définie comme le transport organisé d'un groupe (masse) de voyageurs par voie maritime, à des fins ludiques.

\section{Revue de littérature}

L'étude de la croisière par l'approche quantitative présente certains problèmes. La croisière transcendant les frontières, son industrie ne possède pas d'organisme unique chargé de la collecte des données. II faut ainsi s'en remettre à plusieurs organismes regroupant les voyagistes pour obtenir un portrait juste de cette industrie. En Amérique du Nord, la Cruise Lines International Association (CLIA) constitue l'une des principales voix de l'industrie, tandis que la Passenger Ship Association (PSA) couvre l'Europe. Pour sa part, GP Wild International couvre le reste du monde. Quant à l'Association of Antarctic Tour Operators (IAATO), elle compile les données pour le territoire polaire austral.

Du côté des études qualitatives, il reste beaucoup à faire. Malgré l'ampleur du phénomène, les études sur le tourisme de croisière viennent tardivement. Yarnal (2004 : 353) estime que la croisière a longtemps été boudée dans les rangs universitaires. Essuyant les contrecoups d'une image négative, au même titre que le tourisme de masse, la croisière est ainsi repoussée dans la hiérarchie des sujets de calibre scientifique. Au meilleur des connaissances de l'auteur, une seule revue scientifique a consacré un numéro entier au phénomène de la croisière (le défunt Journal of Tourism Studies, en 1996). Cette édition apporte un premier éclairage sur une industrie en pleine expansion. D'autres études suivent ensuite par vagues. Quelques chercheurs (Douglas et Douglas, 1996 ; Dwyer et Forsyth, 1998) se penchent sur les aspects économiques du phénomène. Certains (Ritter et Schaffer, 1998 ; Wood, 2000) documentent l'aspect environnemental de la croisière. Le volet marketing fait aussi l'objet d'un certain intérêt (Douglas et Douglas, 1996 ; Teye et Leclerc, 1998 ; Wood, 2000 ; Petrick et al., 2007). Weaver (2005) se préoccupe par ailleurs du phénomène de "McDonalisation » de la croisière. La question, controversée, est de savoir si les produits offerts par l'industrie de la croisière ont tendance à l'homogénéisation ou au contraire à la différenciation. Ce débat ne fait que commencer.

D'autres aspects sont aussi étudiés, comme l'impact des croisières sur les petites communautés maritimes (Wilkinson, 1999 ; Jaakson, 2004). La sécurité est au compte des nouveaux thèmes abordés en relation avec l'espace touristique maritime. C'est le cas de Lois et ses collaborateurs (2004) et de Jabour (2007). Enfin, le développement et la montée des croisières polaires (phénomène à l'intérieur du phénomène) voient un nombre important d'auteurs (une cinquantaine) étudier le phénomène sous divers angles ${ }^{1}$.

Les études sociologiques sur l'expérience des visiteurs arrivent en dernier. D'une part, la société actuelle tend à favoriser davantage l'individu (dans son originalité et/ou sa marginalité) plutôt que le groupe. La reproduction à grande échelle de plusieurs comportements de voyage (lors des croisières) similaires à ceux documentés dans les autres grandes infrastructures touristiques contribue sans doute également à ce que le navire soit ignoré comme environnement propice aux grandes études du tourisme. II faut dire aussi que, par sa mobilité, la croisière, contrairement aux autres produits du tourisme, nécessite des enquêtes de terrain coûteuses et difficiles à financer. En outre, l'étude du tissu social, lorsque l'acteur est en vacances, n'est pas facile à réaliser. Elle nécessite la méthode d'observation participante, de longue haleine et, encore une fois, à des coûts élevés.

Quelques études pionnières permettent néanmoins de tracer une première esquisse de la vie de croisière. Ainsi, Grenier (2004) s'intéresse à la relation entre les croisiéristes et l'environnement naturel (polaire), tandis que Petrick (2004), Douglas et Douglas (1999), Yarnal (2004), Graburn (2001) et Yarnal et Kerstetter (2005) se penchent sur les comportements de groupe sur les navires.

D'autres ouvrages, plus généralistes, apportent aussi un éclairage particulier et fort utile à l'analyse de l'industrie des croisières. Dickinson et Vladimir (1996) décrivent l'évolution et la contribution de Carnival Cruise Lines dans le rajeunissement de l'image (et de la clientèle) de la croisière. Cudahy (2001), Mancini (2004) et Gibson (2006) proposent des ouvrages d'analyse sur divers aspects de la croisière et de ses services.

Ce que la plupart de ces recherches ont en commun est l'étude d'une facette de la croisière liée aux retombées économiques, à la vente (marketing) ou, plus récemment, à l'expérience. Les aspects externes de la croisière - sécurité physique et environnementale - restent encore à être abordés. 


\section{De transocéanique à navire de croisière}

L'eau couvre plus de $70 \%$ de la surface de la planète (Lutgens, 1992). Pas étonnant que l'humain ait développé des outils pour franchir les plans d'eau. Le paquebot, et le plus récent navire de croisière, ne sont arrivés que tardivement dans l'histoire de la navigation. La plus récente page de cette histoire, celle de la transformation du paquebot en navire de croisière, ne s'est elle-même effectuée qu'à travers plusieurs décennies marquées par des évolutions technologiques ainsi que par des changements d'ordre socioéconomique et culturel.

Plusieurs étapes ont marqué cette transition (résumées au tableau 1). L'industrie de la croisière doit ses origines à un moyen de locomotion éloigné des mers : le chemin de fer. L'invention du moteur à vapeur révolutionne le transport terrestre en Angleterre, pays de la révolution industrielle (fin du XVIII siècle). Fort de ses réussites en ingénierie, l'un des pères de la Great Western Railway (1833), Isambard K. Brunel, ambitionne d'étendre outre-mer le réseau de la compagnie de chemin de fer, par voie maritime. Son projet ambitieux mène à la construction du S.S. Great Britain, en 1843. Véritable géant des mers avec ses 98 mètres de long, ce paquebot pouvait transporter plus de 600 passagers et 130 membres d'équipage. Premier navire océanique pourvu d'une coque et d'une hélice de fer, il allait contribuer à réduire l'écart entre l'Europe et le nouveau monde. II faudra quelques mois seulement pour convaincre les voyageurs du bienfondé de passer de la technologie désormais désuète des voiles à celle combinée du fer et de la vapeur.
Deux éléments sont intimement liés au succès ou à l'échec des grands projets de transport maritime : les percées technologiques et la fierté nationale. Dans un premier temps, le développement et l'innovation technologiques de l'ère industrielle originent en partie des besoins engendrés par la construction de méga infrastructures mobiles et autonomes. II s'agit d'assurer la stabilité du paquebot, sa ponctualité et sa rapidité. Celle-ci est récompensée annuellement par la remise du Ruban Bleu, prix décerné à partir de 1833 aux navires réduisant l'écart de durée de voyage entre l'Europe et le nouveau monde (qui n'a d'ailleurs pas été attribué depuis le record de 1990 du S.S. United States). Le Ruban fait la fierté des voyagistes et des ingénieurs des chantiers navals et répond aussi à un besoin de nourrir l'amour propre des diverses nations européennes qui s'identifient à ces méga structures.

\section{Tableau 1}

\section{Étapes marquantes de l'évolution de la croisière dans le temps}

\begin{tabular}{|c|c|}
\hline Fin XVIII siècle & $\begin{array}{l}\text { La révolution industrielle, en Angleterre, marque le début de changements importants, notamment en relation avec la production } \\
\text { d'énergie (moteur à vapeur), l'organisation du travail et la division du temps (liées à l'organisation des transports). }\end{array}$ \\
\hline 1818 & $\begin{array}{l}\text { Black Ball Line, de New York, est la première compagnie de transport maritime à offrir un service de transit régulier aux passagers } \\
\text { entre les États-Unis et l'Angleterre. }\end{array}$ \\
\hline Années 1830 & $\begin{array}{l}\text { Arrivée des navires à vapeur (transocéaniques) : } \\
\text { domination des mers par les compagnies transocéaniques britanniques (dont la British and North American Royal Mail Steam } \\
\text { Packet, plus tard Cunard Line). }\end{array}$ \\
\hline 4 juillet 1840 & Samuel Cunard inaugure le transport des passagers entre l'Europe (Liverpool) et l'Amérique (New York). \\
\hline 1843 & $\begin{array}{l}\text { Le S.S. Great Britain est le premier navire transocéanique construit en acier et propulsé par une hélice. C'est alors aussi le plus } \\
\text { grand navire, capable de transporter } 730 \text { passagers et membres d'équipage. }\end{array}$ \\
\hline 1844 & $\begin{array}{l}\text { Le Britannia (premier navire à opérer pour Cunard) transporte une vache à son bord afin de produire du lait frais pour ses passagers. } \\
\text { La traversée de l'Atlantique Nord prend } 14 \text { jours. }\end{array}$ \\
\hline $\begin{array}{l}\text { Années } 1850 \text { et } \\
1860\end{array}$ & $\begin{array}{l}\text { P\&O (Peninsula and Oriental Steam Navigation Company) organise des traversées entre l'Angleterre, l'Espagne et le Portugal de } \\
\text { même qu'en Asie. } \\
\text { De plus en plus de navires se consacrent entièrement au transport des passagers, reléguant le cargo à des navires spécialisés. }\end{array}$ \\
\hline 1867 & $\begin{array}{l}\text { Mark Twain écrit le récit de son périple de six mois comme passager à bord du Quaker City qui effectue la première croisière } \\
\text { organisée à partir des États-Unis (vers l'Égypte et la Grèce). Son livre Innocents Abroad contribue à faire connaître ce nouveau type } \\
\text { de voyage au public. }\end{array}$ \\
\hline Années 1880 & $\begin{array}{l}\text { Le British Medical Journal reconnaît la valeur curative des voyages en mer et encourage le public à participer à des traverses } \\
\text { ludiques de l'Atlantique. }\end{array}$ \\
\hline 1897 & $\begin{array}{l}\text { Les Allemands se lancent dans la conquête des mers. La Hamburg-America gère deux navires, le Deutchland et le Kron-prinz } \\
\text { Wilhelm. De petite capacité (2000 passagers), ces navires manquent plutôt de confort. }\end{array}$ \\
\hline Années 1900 & 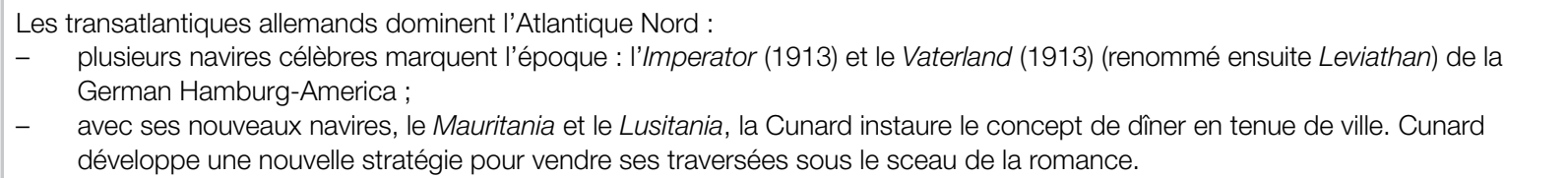 \\
\hline
\end{tabular}




\begin{tabular}{|c|c|}
\hline 1911 et 1912 & $\begin{array}{l}\text { Entrée en service de l'Olympic (1911) et du Titanic (1912), tous deux propriétés de la White Star. L'Olympic atteint un niveau de luxe } \\
\text { alors inégalé avec une piscine et un court de tennis. }\end{array}$ \\
\hline 14 avril 1912 & $\begin{array}{l}\text { Le Titanic (2223 passagers) sombre après avoir heurté un iceberg, faisant plus de } 1500 \text { morts. Le naufrage pose pour la première } \\
\text { fois ouvertement la question de la sécurité des passagers. }\end{array}$ \\
\hline $1914-1918$ & $\begin{array}{l}\text { La Première Guerre mondiale interrompt le développement de nouveaux navires dans les chantiers navals. Les paquebots sont } \\
\text { réquisitionnés pour le transport des troupes : } \\
\text { les transatlantiques allemands seront donnés à l'Angleterre et aux États-Unis en guise de réparation pour les dommages causés } \\
\text { pendant la guerre. }\end{array}$ \\
\hline $1920-1940$ & $\begin{array}{l}\text { L'âge d'or des transocéaniques : } \\
\text { - } \quad \text { le Normandie (1932, France), le Rex (1931, Italie) et le Conte di Savola (1931, Italie), l'Empress of Britain (1905) et l'Empress of } \\
\quad \text { Australia (1919) (Canadien Pacifique) et les Franconia (1923), Queen Mary (1936) et Queen Elizabeth (1940) (Cunard) ; } \\
\text { - } \quad \text { les touristes américains désireux de visiter l'Europe remplacent les immigrants à bord des navires ; } \\
\text { - } \quad \text { les gens riches et célèbres s'y donnent rendez-vous. }\end{array}$ \\
\hline 1934 & La Cunard fait l'acquisition de la White Star et devient la Cunard White Star. \\
\hline 1938-1945 & Deuxième Guerre mondiale : les paquebots sont à nouveaux réquisitionnés pour le transport des troupes alliées. \\
\hline 1958 & $\begin{array}{l}\text { L'arrivée du jet marque la fin des traversées océaniques : } \\
\text { une majorité de voyagistes se départit de ses navires ou déclare faillite. }\end{array}$ \\
\hline Années 1960 & $\begin{array}{l}\text { Un entrepreneur américain, Ted Arison, lance, pour la Norwegian Caribbean Lines (NCL), deux croisières à partir de la Floride. Les } \\
\text { deux navires, le Sunward et le Starward, atteignent ainsi plus rapidement les destinations soleil que s'ils étaient partis de New York } \\
\text { (port d'attache traditionnel des paquebots). } \\
\text { Le rôle du navire est repensé : le transatlantique devient navire de croisière et se concentre sur les destinations chaudes (Caraïbe et } \\
\text { Méditerranée). } \\
\text { Le produit rencontre un tel succès qu'en } 1967 \text { des investisseurs norvégiens et américains s'unissent pour former la Royal } \\
\text { Caribbean Cruise Lines (RCCL). Miami devient le centre d'opération des croisières à destination de la Caraïbe. }\end{array}$ \\
\hline 1970 & $\begin{array}{l}\text { Carnival, un nouveau voyagiste, connaît un grand succès avec son concept de fun ship. } \\
\text { Rajeunissement des croisiéristes et boom du nombre de ceux-ci. }\end{array}$ \\
\hline 1977-1986 & Consolidation et popularisation de l'image de la croisière par le biais de la série télévisée The Love Boat. \\
\hline 1991 & $\begin{array}{l}\text { Première traversée touristique maritime du passage du Nord-Est (Russie). } \\
\text { Première croisière touristique à atteindre le pôle Nord. }\end{array}$ \\
\hline 1992 & Première croisière touristique du Grand Antarctique (secteur australien) (Kapitan Khlebnikov). \\
\hline 1996-1997 & Première circumnavigation touristique de l'Antarctique (Kapitan Khlebnikov). \\
\hline 1999 & Première circumnavigation touristique de l'Océan Arctique (Kapitan Dranitsyn). \\
\hline $\begin{array}{l}23 \text { novembre } \\
2007\end{array}$ & $\begin{array}{l}\text { L'Explorer (154 passagers), premier navire entièrement voué au tourisme, coule au large des îles Shetland du Sud (Antarctique). Le } \\
\text { naufrage ne fait aucune victime, mais relance la question de la sécurité de la navigation de plaisance en milieux extrêmes. }\end{array}$ \\
\hline
\end{tabular}

En effet, la domination de l'Angleterre sur les mers fait l'envie de plusieurs nations, dont les Allemands, les Français et les Italiens, qui rivalisent d'ingéniosité pour arriver à construire le navire capable de décrocher le Ruban Bleu. L'invention du système de ballast qui permet de stabiliser le navire en mer, l'aménagement de style de l'intérieur des navires, les jeux de miroirs qui donnent aux petits espaces un effet de grandeur, les croisiéristes les doivent à la rivalité que chaque pays entretien dans ses chantiers navals.
La construction de ces infrastructures est en partie une affaire d'État (en Europe seulement, pas aux États-Unis, ce qui explique l'absence de tradition maritime chez les Américains) ; les compagnies de transport maritime dépendent aussi surtout des passagers pour financer les chantiers. C'est aux vagues d'immigration massive hors d'Europe que les armateurs doivent la rentabilité des opérations. En 1921, un changement dans la loi américaine de l'immigration, restreignant le nombre de nouveaux arrivants en sol américain, portera un premier coup à la rentabilité des paquebots. À défaut d'immigrants, les voyagistes créent une troisième classe pour touristes à budget.

Les années 1920 et 1930 constituent l'âge d'or du transport maritime. À cette époque, la traversée de l'Atlantique sur les grands paquebots constitue une fenêtre incontournable pour les élites comme pour les parvenus. La classe moyenne, qui commence à disposer d'un revenu discrétionnaire, se laisse séduire par l'idée d'une traversée en mer. Le cinéma contribue à publiciser la traversée. Les voyagistes rivalisent pour attirer et publiciser le 
passage des personnalités les mieux cotées. Le navire devient ainsi le terrain de jeux des classes sociales pour bourgeois et parvenus à la recherche de nouvelles affiliations.

Chacune des grandes guerres impose un arrêt complet des traversées transocéaniques. Les grands paquebots servent alors au transport des troupes, permettant les déplacements de milliers d'hommes vers les terrains de conflit.

L'après-guerre marque le retour en force du public vers les grands navires. Cette période, de 1945 aux années 1950, voit une croissance sans précédent du voyage d'agrément par paquebot (Cudahy, 2001 : xiv). La reconstruction de l'Europe stimule l'imaginaire américain. La société de consommation encourage aussi aux plaisirs dont les navires se font le porteétendard. La mise en service le 26 octobre 1958 par Pan Am d'une route aérienne régulière entre les États-Unis et l'Europe annonce la fin du prestigieux Ruban Bleu et d'une époque. La traversée de l'Atlantique n'est plus qu'une affaire d'heures. Le succès de l'aviation est instantané : du jour au lendemain, les voyageurs et les touristes désertent les paquebots et leurs équipages. Des quelque 70000 passagers recensés en 1955 pour une traversée de l'Atlantique vers New York, le même parcours ne soulève l'intérêt que de 85000 personnes en 1974 (Cudahy, 2001 : xiv). Plusieurs navires terminent « à la ferraille ».

\section{La renaissance du navire}

En s'étendant aux diverses destinations, l'aviation commerciale rend absurde l'existence même du paquebot. II s'en trouve cependant pour défendre le grand navire, par exemple R.W. Robson, éditeur du Pacific Islands Monthly, mensuel consacré au voyage dans les îles du Pacifique, qui écrit, en 1950 :

The average tourist [...] does not want to be hurled across the world, ten thousand feet above the clouds, at 300 miles per hour. He wants to forget the more mundane things, sit in a deck chair, watch blue water slip by, share the pleasures of ship-board life. To see new places, new faces certainly - but to come back to the comfort of a good cabin on a well-found ship when he wishes [...] It is doubtful that tourism by air will ever have the subtle appeal of a cruise or round trip by sea. (Robson, 1950 : 26 cité dans Douglas et Douglas, $1996: 5)$

Si Robson voit juste, il faut encore vingt ans pour vivre le retour véritable du navire. Le déclin des paquebots s'échelonne jusqu'au début des années 1970 (OECD/OCDE, 1970). À cette époque, le début du tourisme de masse, rendu possible par le transport aérien, s'oriente vers les destinations soleil. À défaut de trouver leur raison d'être sur les traversées intercontinentales, les derniers navires ayant survécu au déclin maritime se réorientent aussi vers le soleil (dont la Caraïbe), mais toujours à partir du même port d'attache. De New York, notamment, la traversée vers le soleil de la Carailbe est longue. C'est un entrepreneur américain, Ted Arison, qui, à la fin des années 1960, a l'idée de lancer les croisières à partir de Miami. II y organise deux départs pour la Norwegian Caribbean Lines (NCL). La formule est un succès.

Les gestionnaires prennent alors conscience de la complémentarité naturelle qui unit le transport aérien au transport maritime. Désormais, l'avion servira à rassembler et à amener les croisiéristes du nord du continent vers Miami. Le temps ainsi récupéré peut être mieux investi dans la durée des croisières en milieux «soleil ». Le navire sert désormais d'hôtel flottant, transportant les passagers d'escale en escale. Soutenue par les cultures enjouées de la Caraïbe, la vie à bord du navire se fait décontractée et festive. Le transocéanique n'est plus : vive la croisière ! Miami devient ainsi le centre opérationnel des croisières à destination de la Caraïbe. Pour cette ville, alors en déclin, l'industrie des croisières, avec les infrastructures et les services qu'elle nécessite, devient un moteur économique vital.

Près de quarante ans plus tard, Miami demeure la capitale mondiale de la croisière, siège d'une industrie tout aussi dynamique. En une seule décennie (1995-2005), le nombre de croisiéristes a connu une augmentation de $100 \%$ (voir tableau 2). Le nombre de lits disponibles sur les navires est passé de 35 millions en 1997 à 64 millions en 2002 (Ebersold, 2004). Cruise Industry News (CIN, 2008) estime que l'industrie

\section{Tableau 2}

\section{Croissance annuelle du nombre de passagers (en milliers)}

\begin{tabular}{r|c|c|c}
\hline & $\begin{array}{c}\text { Amérique } \\
\text { du Nord }\end{array}$ & $\begin{array}{c}\text { Reste } \\
\text { du monde }\end{array}$ & $\begin{array}{c}\text { Total } \\
\text { Monde }\end{array}$ \\
\hline 1980 & 1431 & & \\
\hline 1990 & 3496 & 278 & 3774 \\
\hline 1991 & 3834 & 334 & 4168 \\
\hline 1991 & 3834 & 362 & 4385 \\
\hline 1993 & 4318 & 410 & 4728 \\
\hline 1994 & 4314 & 486 & 4800 \\
\hline 1995 & 4223 & 498 & 4721 \\
\hline 1996 & 4477 & 493 & 4970 \\
\hline 1997 & 4864 & 516 & 5380 \\
\hline 1998 & 5243 & 625 & 5868 \\
\hline 1999 & 5690 & 647 & 6337 \\
\hline 2000 & 6546 & 668 & 7214 \\
\hline 2001 & 6637 & 862 & 7499 \\
\hline 2002 & 7472 & 1176 & 8648 \\
\hline 2003 & 7990 & 1536 & 9526 \\
\hline 2004 & 8870 & 1590 & 10460 \\
\hline 2005 & 9671 & 1509 & 11180 \\
\hline & & & \\
\hline Croissance moyenne & $7,6 \%$ \\
annuelle 1980-2005 & & \\
\hline
\end{tabular}

Source : CLIA (2006).

mondiale de la croisière connaîtra un taux de croissance de 5,8 \% en 2008 ; $6,8 \%$ en 2009 ; 8 \% en 2010 ; 4,6 \% en 2011 et $2,5 \%$ en 2012. Ce sont les produits de croisière européens qui connaissent la plus grande part de cette croissance avec une augmentation de $24 \%$ par rapport à 2007 (CIN, 2008). Les passagers proviennent principalement d'Amérique du Nord.

À elle seule, l'industrie de la croisière compte sur un chiffre d'affaires estimé à 15 milliards de dollars américains. Elle procure annuellement plus de 100000 emplois à des membres d'équipage et à plus de 15000 personnes au sol (Ward, 2001). La construction de nouveaux navires est elle aussi en progression. En 2004, on dénombrait une vingtaine de navires de croisière en construction dans le monde pour 48000 nouvelles places d'hébergement en mer (Ebersold, 2004 : 2).

Si le nombre de croisiéristes est en hausse, la durée des séjours sur les navires a 
tendance, elle, à baisser (la durée moyenne des croisières en mer est de sept jours CLIA, 2006). Cette diminution de la durée des voyages en mer est attribuée à l'augmentation du nombre de croisières de courte durée (2 à 5 jours).

Outre la Cunard qui maintient un service transocéanique (Queen Mary 2) entre Liverpool et New York, d'autres voyagistes sont présents aux quatre coins du monde. Pour les croisières de courte durée (moins de 8 jours), la Caraïbe, le Mexique et les Bermudes demeurent des choix populaires. Du côté des croisières d'une semaine ou plus, l'Alaska, le Sud européen (Méditerranée) et la Scandinavie occupent le premier rang. D'autres marchés suivent de près : l'Australasie et l'Asie du Sud-Est, notamment. L'Amérique latine et l'Afrique ne sont pas en reste et possèdent aussi des circuits prisés. L'Arctique demeure un marché spécialisé, tandis que certains géants de la croisière commencent à s'intéresser à l'Antarctique. Cela n'est pas sans inquiéter les petits voyagistes (regroupés sous I'IAATO) qui jouissent d'un quasi-monopole depuis près de vingt ans.

Les escales, première raison d'être des croisières, jouent un rôle beaucoup moins essentiel. La congestion pourrait en être une des raisons. Du mode de transport océanique qu'il était, le navire est devenu une destination en soi. Le croisiériste achète aussi bien le navire-infrastructure que le programme de divertissement lui-même.

Cette demande croissante pour le tourisme de croisière et le besoin de renouveler les flottes des années 1970 stimulent les voyagistes à recruter de nouveaux navires, et les armateurs à en construire d'autres, toujours plus grands. Le tableau 3 présente quelquesuns des plus importants navires de croisière, selon leur nombre de passagers. On y observe qu'environ le tiers des quelque 280 navires de croisière de la planète se trouvent dans la catégorie des grands navires. On recense au moins six navires capables de transporter plus de 3000 passagers et 13 vaisseaux capables d'en accommoder de 2500 à 3000 . Au moins 56 des navires listés sont dans la catégorie des 1500 à 2500 passagers. La majorité des autres (environ une centaine) accueillent moins de 1000 passagers. On remarque aussi le nombre de grands navires entre les mains d'un petit groupe de voyagistes (Royal Caribbean, Princess, Carnival, NCL, Cunard et Disney). Cette concentration s'explique par les coûts de construction et de fonctionnement des navires que seuls les géants peuvent défrayer.

Le seul marché qui échappe encore à ces entrepreneurs est celui des eaux polaires, Antarctique (principalement) et Arctique. La navigation en eaux polaires nécessite des navires construits pour résister à certains types de glace. Or, jusqu'à récemment, les navires de croisière n'étaient pas conçus pour ces destinations. Les navires russes ont longtemps dominé au sein de la flotte polaire affectée au tourisme. Leur retraite prochaine, due au vieillissement, risque de pousser les armateurs à concevoir des navires multi-régions. Une hausse du nombre de navires pourrait rendre la supervision de cette forme de tourisme plus problématique. II ne resterait alors que des questions environnementales et de sécurité pour freiner l'industrie dans ces espaces éloignés.

Le navire de croisière actuel n'a plus rien en commun avec les paquebots de l'âge d'or du voyage maritime. Depuis les années 1970, les progrès scientifiques et les percées technologiques ont grandement contribué à renouveler les concepts entourant le navire de croisière, de sa mécanique à sa production énergétique ; du design de ses cabines aux services alimentaires (Lois et al. 2004 : 93). Les nouveaux navires sont aussi tenus au respect des nouvelles approches environnementales (gestion des déchets, production de l'eau potable, meilleure efficacité énergétique, etc.).

Le navire de croisière des années 2000 promet d'être encore plus grand. Armateurs et voyagistes souhaitent ainsi construire des navires qui pourront accommoder plus de 4000 passagers pour tirer profit d'une économie d'échelle. Plus la capacité de servir d'une même infrastructure est grande, moins ses coûts d'exploitation par passager sont élevés (Lois et al., 2004 : 93-94). Les grands navires ont aussi l'avantage d'offrir plus de possibilités de divertissement (Gibson, 2006 : 3). Avec des infrastructures pouvant s'élever à une hauteur d'au-delà de vingt étages, le navire moderne dispose désormais des espaces nécessaires pour offrir à ses passagers la plus grande variété d'activités sportives et de loisirs, sans qu'ils aient à quitter le vaisseau.

Aux traditionnelles salles de spectacles s'ajoutent les galeries d'art, suffisamment de boutiques pour former un centre commercial, des chapelles pour célébrer les mariages, des centres de la petite enfance, des discothèques pour adolescents, des bibliothèques et des cliniques de santé (avec programmes de régime minceur). Les activités sportives ne sont pas en reste : piscines (avec toit rétractable pour les jours de pluie), jeux de glissade (ill. 3), spas, terrains de frappe (golf), allées de quilles et patinoires. Chaque nouvelle génération de navires emprunte davantage au parc thématique, s'affirmant ainsi non seulement comme une destination en soi, mais comme une destination maritime mobile.

À l'autre bout du spectre, les plus petits navires (150 passagers et moins) présentent aussi des avantages. En plus d'offrir une expérience de voyage plus intime, ces navires, en raison de leur flexibilité quant à la nature des infrastructures portuaires requises, accèdent à des destinations inaccessibles aux grands navires. Dans leur transformation, les grands navires développent des moyens pour gérer les inconvénients générés par leur taille (embouteillages aux points d'accès et dans les villes portuaires visitées). Pour remédier à ce genre de situation, les paquebots s'équipent de plus petits navires qui, comme des autobus flottants, voient au transfert des passagers vers le lieu d'escale. Dans les stations balnéaires les plus achalandées, les voyagistes obtiennent des droits de passage pour garantir à leurs clientèles des plages exclusives, moins bondées.

\section{Les croisiéristes et l'expérience}

La croisière n'en est pas à une contradiction près. D'une part, le croisiériste, comme tous les autres touristes, recherche l'exclusivité (la distinction de Bourdieu, 1979) et l'authenticité. D'autre part, la massification - Adam Weaver (2005) parle de « McDonalisation »et la " fantaisisation » (ou disneyfication) des navires font en sorte que le croisiériste évolue à la fois dans un univers de voyage de plus en plus anonyme, mais aussi de plus en plus détaché de la réalité, comme s'il préférait l'inauthentique décor de voyage à l'authenticité du quotidien. Dans son modèle de l'expérience touristique, Jafari (1988 : 60) associe 
Tableau 3

Échantillon des navires de croisière, par capacité de charge (passagers)

\begin{tabular}{|c|c|c|c|c|c|c|c|}
\hline Rang & Navire & Voyagiste & $\begin{array}{l}\text { Année de } \\
\text { lancement }\end{array}$ & Tonnage & $\begin{array}{l}\text { Nombre de } \\
\text { passagers }\end{array}$ & $\begin{array}{c}\text { Membres } \\
\text { d'équipage }\end{array}$ & Autres \\
\hline \multicolumn{8}{|c|}{3000 passagers et plus (6 navires) } \\
\hline $\begin{array}{l}1 . \\
2 .\end{array}$ & $\begin{array}{l}\text { Adventure of the Seas } \\
\text { Explorer of the Seas }\end{array}$ & \multirow{3}{*}{ Royal Caribbean } & $\begin{array}{l}\text { Nov. } 2001 \\
\text { Oct. } 2000\end{array}$ & $\begin{array}{l}142000 \\
137308\end{array}$ & $\begin{array}{l}3114 / 3838 \\
3114 / 3840\end{array}$ & \multirow{3}{*}{1185} & \multirow{3}{*}{$\begin{array}{l}\text { Casino, } 3 \text { piscines, } 6 \text { bains à } \\
\text { remous, bibliothèque }\end{array}$} \\
\hline 3. & Mariner of the Seas & & $\begin{array}{l}\text { Printemps } \\
2004\end{array}$ & & $3114 / 3840$ & & \\
\hline $\begin{array}{l}4 . \\
5 .\end{array}$ & $\begin{array}{l}\text { Navigator of the Seas } \\
\text { Voyager of the Seas }\end{array}$ & & $\begin{array}{l}\text { Printemps } \\
2003 \\
\text { Mai } 1998\end{array}$ & 137276 & $3114 / 3835$ & & \\
\hline 6. & Caribbean Princess & Princess & Avril 2004 & 116000 & $3114 / 3782$ & 1163 & $\begin{array}{l}\text { Casino, } 4 \text { piscines, } 9 \text { bains à } \\
\text { remous, bibliothèque }\end{array}$ \\
\hline \multicolumn{8}{|c|}{$2500-2599$ passagers (13 navires) } \\
\hline $\begin{array}{r}7 . \\
8 . \\
9 . \\
10 .\end{array}$ & $\begin{array}{l}\text { Carnival Conquest } \\
\text { Carnival Glory } \\
\text { Carnival Liberty } \\
\text { Carnival Valor }\end{array}$ & \multirow[t]{2}{*}{ Carnival } & $\begin{array}{l}\text { Déc. } 2002 \\
\text { Juil. } 2003 \\
\text { Juil. } 2005 \\
\text { Déc. } 2004\end{array}$ & $\begin{array}{l}110329 \\
110000 \\
110000 \\
110329\end{array}$ & $2974 / 3700$ & 1160 & $\begin{array}{l}\text { Casino, } 3 \text { piscines, sauna, } \\
\text { massage, bibliothèque }\end{array}$ \\
\hline $\begin{array}{l}11 . \\
12 .\end{array}$ & $\begin{array}{l}\text { Carnival Triumph } \\
\text { Carnival Victory }\end{array}$ & & $\begin{array}{l}\text { Oct. } 1999 \\
\text { Août } 2000\end{array}$ & 101509 & $2758 / 3473$ & 1100 & $\begin{array}{l}\text { Casino, } 3 \text { piscines, } 7 \text { bains à } \\
\text { remous, bibliothèque }\end{array}$ \\
\hline 13. & Sapphire Pri & Princess & Août 1967 & 115875 & $2670 / 3100$ & 1328 & $\begin{array}{l}\text { Casino, } 4 \text { piscines, } 9 \text { bains à } \\
\text { remous, bibliothèque }\end{array}$ \\
\hline 15. & Queen Mary 2 & Cunard & Jan. 2004 & 148528 & $2620 / 3090$ & 1254 & $\begin{array}{l}3 \text { piscines extérieures, } \\
2 \text { piscines intérieures, } 8 \text { bains } \\
\text { à remous, sauna, massage, } \\
\text { bibliothèque }\end{array}$ \\
\hline $\begin{array}{l}16 . \\
17 . \\
18 . \\
19 .\end{array}$ & $\begin{array}{l}\text { Diamond Princess } \\
\text { Golden Princess } \\
\text { Grand Princess } \\
\text { Star Princess }\end{array}$ & Carnival & $\begin{array}{l}\text { Fév. } 2004 \\
\text { Mai } 2001 \\
\text { Mai } 1998 \\
\text { Fév. } 2002\end{array}$ & $\begin{array}{l}115875 \\
108865 \\
108806 \\
108977\end{array}$ & $\begin{array}{l}2674 / 3100 \\
2600 / 3100 \\
2600 / 3100 \\
2602 / 3102\end{array}$ & $\begin{array}{l}1238 \\
1100 \\
1100 \\
1200\end{array}$ & $\begin{array}{l}\text { Casino, } 4 \text { piscines, } 9 \text { bains à } \\
\text { remous, bibliothèque }\end{array}$ \\
\hline \multicolumn{8}{|c|}{$2000-2499$ passagers (28 navires) } \\
\hline $\begin{array}{l}20 . \\
21 .\end{array}$ & $\begin{array}{l}\text { Majesty of the Sea } \\
\text { Monarch of the Seas }\end{array}$ & \multirow[t]{2}{*}{ Royal Caribbean } & $\begin{array}{l}\text { Avril } 1992 \\
\text { Nov. } 1991\end{array}$ & $\begin{array}{l}73941 \\
73937\end{array}$ & $\begin{array}{l}2380 / 2774 \\
2384 / 2774\end{array}$ & $\begin{array}{l}827 \\
858\end{array}$ & \multirow{2}{*}{$\begin{array}{l}\text { Casino, } 2 \text { piscines, } 2 \text { bains à } \\
\text { remous, bibliothèque }\end{array}$} \\
\hline 22. & Sovereign of the Seas & & Jan. 1988 & 73192 & $2306 / 2882$ & 825 & \\
\hline $\begin{array}{l}23 . \\
24 .\end{array}$ & $\begin{array}{l}\text { Norwegian Star } \\
\text { Norwegian Dawn }\end{array}$ & $\mathrm{NCL}$ & $\begin{array}{l}\text { Déc. } 2001 \\
\text { Oct. } 2002\end{array}$ & $\begin{array}{l}91794 \\
91740\end{array}$ & $\begin{array}{l}2244 / 4080 \\
2224 / 2080\end{array}$ & $\begin{array}{l}1100 \\
1318\end{array}$ & $\begin{array}{l}\text { Casino, } 2 \text { piscines extérieures, } \\
1 \text { piscine intérieure, } \\
4 \text { bains à remous, } \\
1 \text { bain à remous } \\
\text { pour enfants, cinéma et } \\
\text { bibliothèque }\end{array}$ \\
\hline $\begin{array}{l}25 . \\
26 . \\
27 . \\
28 .\end{array}$ & $\begin{array}{l}\text { Carnival Legend } \\
\text { Carnival Miracle } \\
\text { Carnival Pride } \\
\text { Carnival Spirit }\end{array}$ & Carnival & $\begin{array}{l}\text { Août } 2002 \\
\text { Avril } 2004 \\
\text { Jan. } 2002 \\
\text { Avril } 2001\end{array}$ & $\begin{array}{l}85920 \\
85920 \\
85920 \\
85920\end{array}$ & $\begin{array}{l}2124 / 2680 \\
2124 / 2680 \\
2124 / 2680 \\
2124 / 2680\end{array}$ & $\begin{array}{l}1030 \\
961 \\
1029 \\
930\end{array}$ & $\begin{array}{l}3 \text { piscines extérieures dont } \\
1 \text { pour enfants, } 1 \text { piscine } \\
\text { intérieure, } 5 \text { bains à remous, } \\
\text { sauna, massage, bibliothèque }\end{array}$ \\
\hline $\begin{array}{l}29 . \\
30 .\end{array}$ & $\begin{array}{c}\text { Costa Atlantica } \\
\text { Costa Mediterranea }\end{array}$ & Costa & $\begin{array}{l}\text { Juil. } 2000 \\
\text { Mai } 2003\end{array}$ & $\begin{array}{l}85700 \\
85700\end{array}$ & $\begin{array}{l}2112 / 2680 \\
2112 / 2680\end{array}$ & $\begin{array}{l}920 \\
920\end{array}$ & $\begin{array}{l}2 \text { piscines extérieures, } \\
1 \text { piscine intérieure/ } \\
\text { extérieure, } 1 \text { bain à remous, } \\
\text { bibliothèque }\end{array}$ \\
\hline $\begin{array}{l}31 . \\
32 . \\
33 . \\
34 .\end{array}$ & $\begin{array}{l}\text { Jewel of the Seas } \\
\text { Brillance of the Seas } \\
\text { Radiance of the Seas } \\
\text { Serenade of the Seas }\end{array}$ & Royal Caribbean & $\begin{array}{l}\text { Juin } 2004 \\
\text { Juil. } 2002 \\
\text { Avril } 2001 \\
\text { Août } 2003\end{array}$ & $\begin{array}{l}90090 \\
90090 \\
90090 \\
90090\end{array}$ & $\begin{array}{l}2112 / 2500 \\
2100 / 2500 \\
2100 / 2500 \\
2100 / 2500\end{array}$ & $\begin{array}{l}858 \\
869 \\
858 \\
858\end{array}$ & $\begin{array}{l}\text { Casino, } 2 \text { piscines, } 3 \text { bains à } \\
\text { remous, bibliothèque }\end{array}$ \\
\hline
\end{tabular}




\begin{tabular}{|c|c|c|c|c|c|c|c|}
\hline $\begin{array}{l}35 . \\
36 . \\
37 . \\
38 . \\
39 . \\
40 . \\
41 . \\
42 .\end{array}$ & $\begin{array}{l}\text { Fantasy } \\
\text { Ecstasy } \\
\text { Elation } \\
\text { Fascination } \\
\text { Imagination } \\
\text { Inspiration } \\
\text { Paradise } \\
\text { Sensation }\end{array}$ & Carnival & $\begin{array}{l}\text { Mars } 1990 \\
\text { Juin } 1991 \\
\text { Mars } 1998 \\
\text { Juil. } 1994 \\
\text { Juil. } 1995 \\
\text { Avril } 1996 \\
\text { Nov. } 1998 \\
\text { Nov. } 1993\end{array}$ & $\begin{array}{l}70367 \\
70367 \\
70367 \\
70367 \\
70367 \\
70367 \\
70367 \\
70367\end{array}$ & $\begin{array}{l}2056 / 2634 \\
2052 / 2594 \\
2052 / 2594 \\
2052 / 2634 \\
2056 / 2634 \\
2056 / 2634 \\
2052 / 2594 \\
2040 / 2594\end{array}$ & $\begin{array}{l}920 \\
920 \\
920 \\
920 \\
920 \\
920 \\
920 \\
920\end{array}$ & $\begin{array}{l}\text { Casino, } 3 \text { piscines, } 6 \text { bains à } \\
\text { remous, bibliothèque }\end{array}$ \\
\hline $\begin{array}{l}43 . \\
44 . \\
45 .\end{array}$ & $\begin{array}{l}\text { Norwegian Sky } \\
\text { Norwegian Sun } \\
\text { Pride of Aloha }\end{array}$ & $\mathrm{NCL}$ & $\begin{array}{l}\text { N/D } \\
\text { Nov. } 2001 \\
\text { Août } 1999\end{array}$ & $\begin{array}{l}77104 \\
78309 \\
77104\end{array}$ & $\begin{array}{l}2002 / 2400 \\
2002 / 2400 \\
2002 / 2400\end{array}$ & $\begin{array}{l}N / D \\
980 \\
950\end{array}$ & $\begin{array}{l}\text { Casino, } 2 \text { piscines, } 4 \text { bains à } \\
\text { remous, bibliothèque }\end{array}$ \\
\hline $\begin{array}{l}46 . \\
47 .\end{array}$ & $\begin{array}{c}\text { Rhapsody of the Seas } \\
\text { Vision of the Seas }\end{array}$ & Royal Caribbean & $\begin{array}{l}\text { Mai } 1997 \\
\text { Mai } 1998\end{array}$ & $\begin{array}{l}78491 \\
78491\end{array}$ & $\begin{array}{l}2000 / 2435 \\
2000 / 2435\end{array}$ & $\begin{array}{l}765 \\
765\end{array}$ & $\begin{array}{l}\text { Casino, piscine, } 1 \text { piscine } \\
\text { intérieure/extérieure, } 6 \text { bains à } \\
\text { remous, bibliothèque }\end{array}$ \\
\hline \multicolumn{8}{|c|}{1500 - 1999 passagers (28 navires) } \\
\hline $\begin{array}{l}49 . \\
50 .\end{array}$ & $\begin{array}{l}\text { Coral Princess } \\
\text { Island Princess }\end{array}$ & Princess & $\begin{array}{l}\text { Déc. } 2002 \\
\text { Juin } 2003\end{array}$ & 91627 & $1974 / 2590$ & 900 & Casino, 2 piscines, bibliothèque \\
\hline 51. & Norwegian Spirit & $\mathrm{NCL}$ & Oct. 1998 & 75338 & $1966 / 2475$ & 1300 & $\begin{array}{l}\text { Casino, } 2 \text { piscines, } 4 \text { bains à } \\
\text { remous, bibliothèque }\end{array}$ \\
\hline 68. & Queen Elizabeth 2 & Cunard & Mai 1969 & 70327 & $1728 / 1906$ & 1015 & $\begin{array}{l}\text { Casino, piscine intérieure, } \\
\text { piscine extérieure, cinéma, } \\
\text { bibliothèque }\end{array}$ \\
\hline $\begin{array}{l}69 . \\
70 .\end{array}$ & $\begin{array}{l}\text { Disney Magic } \\
\text { Disney Wonder }\end{array}$ & Disney & $\begin{array}{l}\text { Juil. } 1998 \\
\text { Août } 1999\end{array}$ & $\begin{array}{l}83338 \\
85000\end{array}$ & $\begin{array}{l}1754 / 3325 \\
1704 / 3325\end{array}$ & $\begin{array}{l}945 \\
945\end{array}$ & $\begin{array}{l}3 \text { piscines, } 6 \text { bains à remous, } \\
\text { sauna, cinéma }\end{array}$ \\
\hline \multicolumn{8}{|c|}{1000 - 1499 passagers (23 navires) / 999 passagers et moins (plus d'une centaine) } \\
\hline 102. & Marco Polo & Orient Line & Avril 1966 & 22080 & $848 / 915$ & 356 & $\begin{array}{l}\text { Casino, piscine, } 3 \text { bains à } \\
\text { remous, bibliothèque }\end{array}$ \\
\hline 123. & Kapitan Khlebnikov & $\begin{array}{l}\text { Murmansk Shipping } \\
\text { Company/ } \\
\text { Quark Expeditions }\end{array}$ & 1981 & 12288 & $108 / 114$ & 60 & $\begin{array}{l}\text { Piscine extérieure, héliport, } \\
\text { zodiacs }\end{array}$ \\
\hline 102. & Marco Polo & Orient Line & Avril 1966 & 22080 & $848 / 915$ & 356 & $\begin{array}{l}\text { Casino, piscine, } 3 \text { bains à } \\
\text { remous, bibliothèque }\end{array}$ \\
\hline 123. & Kapitan Khlebnikov & $\begin{array}{l}\text { Murmansk Shipping } \\
\text { Company/ } \\
\text { Quark Expeditions }\end{array}$ & 1981 & 12288 & $108 / 114$ & 60 & $\begin{array}{l}\text { Piscine extérieure, héliport, } \\
\text { zodiacs }\end{array}$ \\
\hline
\end{tabular}

Source : Compilation de l'auteur à partir de Ward (2007).

ce détachement aux phases d'émancipation - « sentiment de libération du confinement du quotidien » - et d'animation du voyage - un espace-temps « distinctement non ordinaire ». Ce modèle permet d'expliquer la superficialité dont les touristes, à tord ou à raison, sont souvent accusés. Or, Wang (2000 : 48-49) estime que l'expérience touristique recherchée par nombre de touristes n'est pas celle d'une authenticité d'objets ou de lieux, mais plutôt une authenticité existentielle. Celle-ci se dégage d'expériences qui aident les gens à se sentir plus authentiques que durant la vie régulière. Pour Graburn (2001, cité dans Yarnal et Kerstetter, 2005 : 369), cette authenticité existentielle est davantage réalisable dans des espaces situés hors de l'ordinaire, parce que l'individu est alors libéré de toutes responsabilités et contraintes du quotidien.
Même s'ils n'entretiennent que peu ou le minimum de relations avec les autres vacanciers, les touristes (et c'est encore plus vrai chez ceux qui partagent un espace ludique clos) sont tout de même liés les uns aux autres par le sentiment de liberté retrouvée. Le navire, qu'il soit classique ou fantaisiste, devient ainsi un espace de libération. Malgré l'apparence fermée de ses infrastructures, le navire offre aux passagers l'accès aux surfaces océaniques, qui symbolisent la liberté (absence de restriction routière visuelle, notamment).

Dans le contexte social actuel axé davantage sur le travail et la performance que sur les rapports humains, on observe de plus en plus de croisiéristes voyager avec des membres de la famille élargie (y compris des amis). Ces voyageurs cherchent ainsi à créer des moments d'authenticité existentielle avec les êtres aimés. On retrouve donc, dans la masse de voyageurs qui occupent un espace navire, une multitude de sous-groupes liés par des sentiments affectifs puissants. Contrairement à la ville (où l'on retrouve aussi ces sous-unités sociales), l'espace navire est libéré des contraintes et de plusieurs normes sociales que l'on croit imposées par l'environnement domestique.

Traditionnellement, les Nord-Américains représentent la majorité des croisiéristes : 11200000 passages en 2006 (Ward, 2007 : 44). Ils sont suivis de très loin par les Britanniques (1 200 000), les Allemands (639 000) et les Asiatiques (600 000, sans les Japonais). L'Italie (514 000), I'Espagne (379 000), le Canada (300 000), la France (252 000), la Grèce (104 000), le reste de 
l'Europe, y compris la Scandinavie (250 000) et le Japon (180 000), constituent les autres principaux marchés. En 2006, 9,4 millions d'Américains ont effectué une croisière, représentant à eux seul $78 \%$ du nombre mondial de croisiéristes (BREA, 2007 : 9).

Au-delà des chiffres, il faut souligner que la croisière est un phénomène en pleine expansion, dont les seules limites en cette matière sont celles imposées par la capacité de charge et la disponibilité des navires (''infrastructure). Pour le marché nord-américain, la CLIA estime à 43,5 millions le nombre de personnes qui souhaitent réaliser une croisière dans un avenir proche (OMT, 2003 : 9). La demande est aussi à la hausse dans les autres continents. Les armateurs ont donc toutes les raisons de justifier leurs commandes de construction pour des navires plus nombreux et plus grands.

Jadis réservée aux gens plus fortunés, et par conséquent plus âgés, la croisière aujourd'hui offre des produits adaptés à la plupart des clientèles. L'âge des croisiéristes est à la baisse, leur âge moyen se situant à 46 ans. La moyenne d'âge des croisiéristes qui en sont à leur première expérience est par ailleurs inférieure à 40 ans. Leur revenu familial moyen, aux États-Unis, est de 50000 dollars (OMT, 2003 : 10). Aux clientèles déjà bien représentées (retraités, parents et enfants, gais et lesbiennes) s'ajoutent désormais les familles monoparentales et les groupes multi-générationnels (grandsparents, enfants et petits-enfants). Selon Cartwright et Baird (1999 : 17), les touristes de moins de 50 ans choisissent davantage la croisière pour le divertissement, pour marquer des événements spéciaux, de même que pour l'accès à des services de garde (pour les enfants). Carnival (2005, cité dans Gibson, 2006 : 1) rapporte avoir eu 500000 enfants passagers en 2004, ce qui représentait une augmentation de $400 \%$ sur la décennie précédente. Les passagers de plus de 50 ans choisissent davantage la croisière pour le sentiment de sécurité ainsi que la facilité qu'elle procure (le navire offre tous les services) et les bons soins (se faire dorloter) qui en découlent. Les croisiéristes plus âgés demandent de plus en plus de produits actifs, reflet d'une société plus branchée sur le bien-être.

\section{L'envers du décor}

Comme les autres secteurs de l'industrie du tourisme, la croisière est aussi appelée à tenir compte des divers types de risques associés à la sécurité de sa clientèle, de son personnel et de ses infrastructures terrestres et maritimes. Le bon fonctionnement des infrastructures du navire et de la croisière dépendent d'une quantité de services : approvisionnement en carburant, en eau potable, en aliments, prévisions météorologiques, services d'immigration ; de la sécurité du bâtiment, de l'inspection des aliments, de la gestion des ordures et des eaux usées. Tout doit être pensé, planifié et synchronisé afin d'assurer l'utilisation maximale du temps, de l'espace et des infrastructures dont disposent le navire et son équipage.

Les autorités portuaires doivent aussi disposer de l'espace nécessaire pour accueillir ces infrastructures mobiles. Les navires de croisière nécessitent des quais d'une longueur de 60 à 300 mètres. Dans certaines destinations touristiques, les navires de croisière peuvent monopoliser à eux seuls, le temps de l'escale, une vaste partie, sinon l'ensemble des infrastructures portuaires. Si les voyagistes préfèrent gérer de grands groupes en mer, la situation diffère au sol. II faut par exemple plus de 50 autobus pour desservir les croisiéristes d'un navire de 3000 passagers. À cela, s'ajoutent les formalités de dédouanement et de sécurité dans les divers ports visités qui peuvent entraîner des problèmes de congestion autour du navire, mais aussi des problèmes d'accès au navire. Aux États-Unis, seulement une vingtaine de villes disposent des infrastructures nécessaires pour accueillir les navires de croisière.

\section{Croisière et environnement}

En matière de navigation, la sécurité comprend aussi les mesures pour amenuiser les répercussions des vaisseaux sur l'environnement. Le tableau 4 présente les principaux types d'impacts (négatifs et positifs) que peuvent avoir les navires de croisière. Ces impacts se distinguent selon qu'ils sont directs ou indirects, de même que selon le milieu visé (communauté humaine ou milieu naturel). Notons que certains types d'impacts, par leur nature cumulative, peuvent être nuisibles seulement à long terme.
Au nombre des retombées indirectes de l'industrie des croisières, mentionnons la construction de ces navires dont la livraison représente des milliards de dollars. Par exemple, la commande de la Royal Caribbean Cruises à la firme norvégienne Aker Yard pour la construction d'un second navire de classe Genesis est évaluée à près de 900 millions d'euros (Moskwa, 2007), soit environ 1,42 milliard de dollars canadiens. La construction du navire de 360 mètres de long par 47 mètres de large, pouvant accommoder 8400 passagers et membres d'équipage, est répartie sur trois années au cours desquelles elle rapportera gros au chantier naval de Turku, en Finlande, où 80 à $90 \%$ du navire sera construit. Ce premier navire de type Genesis - navire de passager le plus coûteux de l'histoire maritime - doit être livré en 2009. Près de 8000 emplois liés à la construction des navires auront ainsi été créés sur une période de quatre ans (YLE, 2007).

Tandis que le transport routier et aérien a fait l'objet ces dernières années de pressions sociales et politiques afin de diminuer ses émissions de gaz à effets de serre, le transport maritime, lui, semble avoir échappé au discours. Pourtant, les navires contribuent notamment à l'émission de $\mathrm{CO}_{2}$, d'oxyde nitreux et de dioxyde de souffre. Sur le plan environnemental, les navires de croisière sont assujettis à plus d'une quarantaine de traités internationaux régissant le transport maritime et la navigation qui précisent, entre autres, la façon de gérer une partie de leur pollution (comme les eaux usées - eaux noires, eaux grises, ballast, etc.). La Convention internationale pour la prévention de la pollution par les navires (1973), complétée par le protocole Marpol (marrine pollution) de 1978, est de ce nombre. Cette convention contient six annexes réglementant la prévention de la pollution par les navires (émission de gaz polluants, déversement des eaux usées, etc.). Cependant, une partie de la pollution produite par ceux-ci n'est encore assujettie à aucune règlementation internationale (Wiklund, 2008).

La montée de la conscience environnementale, particulièrement appropriée dans les techniques de vente et de promotion des produits touristiques, force déjà (quoique 
très lentement) armateurs et voyagistes à repenser leurs activités. Les architectes et les concepteurs navals chargés de concevoir la prochaine génération de navires apprend à revoir l'infrastructure même des vaisseaux. Les navires de demain devront notamment être capables de gérer leurs déchets et faire preuve d'une efficacité énergétique supérieure tout en état moins polluante. Le réchauffement climatique engendre aussi des changements sur les surfaces maritimes, avec plus de tempêtes et de vagues creuses, dans certains secteurs. Toutes ces modifications nécessiteront des transformations à la structure même des navires.

\section{Sécurité : Quand la croisière ne s'amuse plus}

Malgré tous les efforts déployés, il peut arriver que des incidents viennent perturber le bon déroulement des croisières. Seuls les incidents spectaculaires (dégâts majeurs, naufrages, épidémies ou opération pirates) atteignent la presse populaire. Lois et ses collaborateurs (2004: 95) ont répertorié 16 incidents sérieux associés à l'industrie de la croisière de 1992 à 2001. Grenier (2003 : 195-197) a aussi observé un nombre fréquent d'incidents lors de croisières polaires aux deux extrémités du globe. Ces incidents incluent les collisions (avec d'autres vaisseaux ou des icebergs), les pannes de moteur et les incendies.
En général, peu d'accidents récents ont entraîné la mort de passagers, à l'exception du naufrage du Cebucity à Manilla Bay en 1994 causant une centaine de morts, ainsi que du naufrage du Royal Pacific dans le détroit de Malacca en 1992, dont le bilan a été de trois morts et six disparus (Lois et al., 2004 : 95). Dans les régions polaires, plusieurs navires se sont échoués depuis la percée de ce type de croisière. Mais les dénouements ont jusqu'à présent été heureux. Deux navires ont cependant été perdus. L'Explorer a sombré au large le 23 novembre 2007 pour des raisons encore inexpliquées, quoiqu'une forte présence de glaces en ce début de saison australe ait pu jouer un rôle dans cet accident. Ce n'était pas le cas en 1989 lorsque le Bahia Paraiso, brise-glace argentin servant également au tourisme, coula par un temps idéal, sans une glace à l'horizon, après avoir entaillé sa proue sur une roche sous la ligne d'eau. Ces incidents rappellent cependant la vulnérabilité des infrastructures et du tourisme aux éléments naturels et à la géographie du terrain marin. Ils rappellent également la nécessité d'établir des plans d'évacuation et de sauvetage adéquat, ce qui n'est pas sans poser un défi supplémentaire, dans plusieurs coins du monde.

Il arrive que des touristes meurent en voyage, de causes naturelles. British Airways, qui transporte chaque année plus de 36 millions de passagers, rapporte annuellement environ 10 décès à bord (Swinford, 2007). On ne connaît pas les données relatives aux navires de croisière. Ces derniers (à l'exception des navires polaires) possèdent des morgues où sont entreposés les corps des personnes décédées (morts naturelles en raison de l'âge ou d'un mauvais état de santé).

Par ailleurs, l'industrie de la croisière a elle aussi subi les contrecoups des attaques terroristes du 11 septembre. D'une part, certains voyagistes n'ont pas survécu à la crise. D'autre part, la subséquente guerre en Iraq a rendu beaucoup de touristes - américains, en particulier - plus timides face au séjour à l'étranger et au transport aérien. Ces touristes optent désormais pour les " croisières domestiques" (homeland cruising). Celles-ci ont comme ports d'attache une vingtaine de grandes villes nordaméricaines (dont Miami, Fort Lauderdale, Seattle, Los Angeles, San Juan, Boston, New York, Vancouver et Honolulu). Elles ont l'avantage de ne pas nécessiter de longs vols vers l'étranger puisque les ports d'attache se trouvent à proximité des régions de résidence des voyageurs. Ces derniers disposent ainsi d'un choix de près de 4000 départs, annuellement. Montréal et la ville de Québec pourraient éventuellement s'ajouter à ces capitales de la croisière "domestique ».

\section{Tableau 4}

\section{Types d'impacts des navires de croisière}

\section{IMPACTS DIRECTS}

IMPACTS INDIRECTS

\begin{tabular}{|c|c|c|c|c|}
\hline & Positifs & Négatifs & Positifs & Négatifs \\
\hline $\begin{array}{l}\text { Sur } \\
\text { l'environnement } \\
\text { naturel }\end{array}$ & $\begin{array}{l}\text { Valorisation des } \\
\text { panoramas naturels, } \\
\text { côtiers et urbains } \\
\text { Possibilité de contribuer à } \\
\text { sensibiliser les croisiéristes } \\
\text { aux milieux marins }\end{array}$ & $\begin{array}{l}\text { Pollution aérienne, marine } \\
\text { et sonore sous-marine } \\
\text { Impact sur les massifs } \\
\text { coraux (ancre) } \\
\text { Perturbation de zones } \\
\text { fauniques }\end{array}$ & $\begin{array}{l}\text { Peu encourager la } \\
\text { conservation d'espaces } \\
\text { naturels }\end{array}$ & $\begin{array}{l}\text { Dégradation de } \\
\text { l'environnement } \\
\text { (traitement des déchets } \\
\text { y compris des eaux usées) }\end{array}$ \\
\hline $\begin{array}{l}\text { Sur les } \\
\text { communautés } \\
\text { humaines locales }\end{array}$ & $\begin{array}{l}\text { Contribution à l'économie } \\
\text { Générateur d'emplois } \\
\text { directs }\end{array}$ & $\begin{array}{l}\text { Congestion des rues } \\
\text { Création de périodes de } \\
\text { pointes saisonnières dans } \\
\text { les services } \\
\text { Générateur d'emplois } \\
\text { saisonniers }\end{array}$ & $\begin{array}{l}\text { Générateur d'emplois / } \\
\text { revenus indirects }\end{array}$ & Acculturation \\
\hline
\end{tabular}

Source : auteur 
Portrait statistique sommaire pour l'industrie nord-américaine de la croisière, 2002-2006

\begin{tabular}{|c|c|c|c|c|c|c|c|c|c|}
\hline & \multirow[b]{2}{*}{2002} & \multirow[b]{2}{*}{2003} & \multirow[b]{2}{*}{2004} & \multirow[b]{2}{*}{2005} & \multirow[b]{2}{*}{2006} & \multicolumn{4}{|c|}{ Croissance moyenne annuelle } \\
\hline & & & & & & 2003 & 2004 & 2005 & 2006 \\
\hline $\begin{array}{l}\text { Capacité } \\
\text { Nombre de navires } \\
\text { Nombre de couchettes inférieures } \\
\text { Couchettes disponibles/jour (millions) }\end{array}$ & $\begin{array}{r}123 \\
197553 \\
61,00\end{array}$ & $\begin{array}{r}134 \\
212004 \\
63,38\end{array}$ & $\begin{array}{r}144 \\
225714 \\
69,95\end{array}$ & $\begin{array}{r}145 \\
230891 \\
74,79\end{array}$ & $\begin{array}{r}151 \\
249691 \\
79,92\end{array}$ & $\begin{array}{l}8,9 \% \\
7,3 \% \\
3,9 \%\end{array}$ & $\begin{array}{r}7,5 \% \\
6,5 \% \\
10,4 \%\end{array}$ & $\begin{array}{l}0,7 \% \\
2,3 \% \\
6,9 \%\end{array}$ & $\begin{array}{l}4,1 \% \\
8,1 \% \\
6,9 \%\end{array}$ \\
\hline $\begin{array}{l}\text { Passagers et revenus globaux } \\
\text { Nombre de passagers (millions) } \\
\text { Nombre de couchettes/jour (millions) } \\
\text { Capacité d'utilisation (couchettes/jour) }\end{array}$ & $\begin{array}{r}9,22 \\
61,47 \\
100,8 \%\end{array}$ & $\begin{array}{r}9,83 \\
66,17 \\
104,4 \%\end{array}$ & $\begin{array}{r}10,85 \\
73,88 \\
105,6 \%\end{array}$ & $\begin{array}{r}11,18 \\
77,78 \\
104,0 \%\end{array}$ & $\begin{array}{r}12,00 \\
83,06 \\
103,9 \%\end{array}$ & $\begin{array}{l}6,6 \% \\
7,6 \%\end{array}$ & $\begin{array}{l}10,3 \% \\
11,7 \%\end{array}$ & $\begin{array}{l}3,1 \% \\
5,3 \%\end{array}$ & $\begin{array}{l}7,3 \% \\
6,8 \%\end{array}$ \\
\hline $\begin{array}{l}\text { Revenus bruts (milliards USD) } \\
\text { Revenus bruts/passager } \\
\text { Revenus bruts/passager/jour }\end{array}$ & $\begin{array}{r}14,28 \$ \\
1549 \$ \\
232 \$\end{array}$ & $\begin{array}{r}14,73 \$ \\
1498 \$ \\
223 \$\end{array}$ & $\begin{array}{r}16,85 \$ \\
1553 \$ \\
228 \$\end{array}$ & $\begin{array}{r}19,17 \$ \\
1715 \$ \\
246 \$\end{array}$ & $\begin{array}{r}20,64 \$ \\
1720 \$ \\
248 \$\end{array}$ & $\begin{array}{r}3,2 \% \\
-3,2 \% \\
-4,2 \%\end{array}$ & $\begin{array}{r}14,4 \% \\
3,6 \% \\
2,4 \%\end{array}$ & $\begin{array}{r}13,8 \% \\
10,4 \% \\
8,1 \%\end{array}$ & $\begin{array}{l}7,7 \% \\
0,3 \% \\
0,8 \%\end{array}$ \\
\hline
\end{tabular}

\section{Coûts et retombées économiques}

La nature commerciale de l'industrie, la compétitivité entre les voyagistes impliqués et l'absence d'un organisme unique rendent difficile la cueillette de données permettant d'approfondir les retombées de l'industrie de la croisière. Les renseignements sont souvent localisés et sans contexte spécifique. II importe aussi de distinguer entre les recettes générées à bord du navire et les retombées économiques pour la destination.

Les recettes générées à bord des navires représentent une part de plus en plus importante des revenus des voyagistes maritimes (jusqu'à $35 \%$ ). Les principales sources de revenus varient d'une croisière à l'autre. Pour certaines, le jeu et la vente de boisson représentent les services les plus profitables. Pour d'autres, comme la Norwegian Cruise Line (NCL), la vente de bijoux (31,9\%) et d'articles de mode (31,6 \%) arrive en tête du palmarès des sources de revenus. Quant au profil du consommateur, le croisiériste européen dépense moins à bord du navire que le voyageur nord-américain (OMT, 2003 : 131). De plus en plus d'activités, offertes à bord, nécessitent un coût de participation ou d'accès (location d'équipement ou accès payant à un bar ou à une salle à manger). Selon l'OMT (2003 : 132), l'argent ainsi gagné « permet en outre de maintenir la consommation dans les limites raisonnables, et de récupérer les millions de dollars investis dans les installations telles que la patinoire ou la salle de réalité virtuelle».

Quant aux revenus générés dans les destinations visitées par les navires, il est très ardu de les évaluer avec exactitude. D'une part, il est très difficile de mesurer où s'arrête l'impact économique des croisiéristes lorsqu'ils font escale. D'autre part, il existe une grande disparité entre les données trouvées dans les différents documents publiés par les organismes portuaires et touristiques (OMT, 2003 : 161).

La situation de la croisière est mieux circonscrite en Amérique du Nord. Le tableau 5 présente un portrait statistique de la situation de l'industrie de la croisière pour ce continent, pour la période 2002-2006. On y apprend que la croissance de l'industrie, quoique continue, est plus modérée. Business Research \& Economic Advisors attribue ce ralentissement de la croissance à la décélération de l'économie américaine. De même, les croisiéristes ont tendance à moins dépenser (en 2006, du moins). Dans l'ensemble, le tableau 5 témoigne d'une industrie en santé avec des revenus qui se sont accrus de 7,7 \% (soit 20,6 milliards de dollars américains) (BREA, 2007 : 7-8).

En Amérique du Nord, $75 \%$ des activités de l'industrie de la croisière se déroulent en territoire américain (Floride, Caraïbe, Côte
Ouest et Alaska, principalement). La Cruise Lines International Association (2008) estime à 37,7 milliards de dollars américains les retombées de l'industrie seulement pour les ports visités aux États-Unis. Certains facteurs expliquent en partie la popularité des croisières à partir des États-Unis ou à destination de la Caraïbe. D'une part, les croisières en Europe ont tendance à être plus coûteuses, d'autre part, la Caraïbe a l'avantage d'offrir des attractions situées à proximité des côtes (plages, parcs d'amusements, casinos, etc.), ce qui n'est pas le cas des attractions d'Europe, plutôt situées à l'intérieur du continent (Londres, Paris, Rome, Euro Disney, etc.). Enfin, le prix du carburant a tendance à être plus élevé en Europe.

Au Canada, la croisière occupe également une place de choix dans l'industrie du tourisme. En 2003, par exemple, 880 navires ont accosté dans un port canadien (BREA, 2004 : 10, dans Legendre, 2006). Cette même année, BREA a recensé 482000 embarquements à travers le pays. Si l'on tient compte des passagers en transit ou en débarquement, le nombre de croisiéristes ayant foulé le sol canadien a alors atteint 1,55 million (Ibid.).

Comme le montre le tableau 6, la ville de Vancouver domine avec près de $60 \%$ du marché canadien. Cette situation n'est pas étrangère au trafic maritime engendré par les 
croisières vers l'Alaska, via l'Inside Passage, pour lesquelles Vancouver sert soit de point de départ, soit d'escale.

Au Québec, en 2004, 159 navires de croisière ont fait escale dans les ports de Québec et de Montréal où ils ont fait débarquer 173000 passagers et membres d'équipage, ce qui représentait une hausse de $24 \%$ par rapport à l'année précédente (Gamache, 2005 : 12). Ces données varient selon les années, la demande et les itinéraires proposés par les voyagistes. Ainsi, en 2006, près de 154000 passagers et membres d'équipage ont effectué 143 escales au Québec (Belzile, 2008 : 8). Au chapitre des revenus, on les évaluait à 134 millions de dollars en 2004 (BREA, 2004, cité dans Gamache, 2005 : 12) et à 77,5 millions de dollars en 2006 (Belzile, 2008 : 8). De plus, ces escales ont contribué au maintien de un millier d'emplois (BREA, 2004, cité dans Gamache, 2005 : 12; Belzile, 2008 : 8).

Précisons que les croisières au Québec ne représentent que $6 \%$ de la performance canadienne, la Côte Ouest (73 \%) et les Maritimes (21\%) le devançant en raison de leur proximité des ports d'embarquement de Seattle, de Boston et de New York d'où origine un volume important de croisières de courte durée à destination du Canada (Belzile, 2008 : 8).

Bien que la navigation ait joué un rôle clé dans l'histoire du Québec, du point de vue du tourisme, le Saint-Laurent est encore avant tout une destination jeune, "en émergence " (Belzile, 2008 : 8). Cherchant à encourager le développement de cette industrie sur son territoire, le gouvernement du Québec a préparé en 2008 une stratégie de développement de l'industrie de la croisière. Ses principaux objectifs sont d'augmenter les recettes touristiques et le nombre de visiteurs " en améliorant la compétitivité » du secteur des croisières par le développement de nouvelles escales comme à Saguenay, à Sept-Îles, à Baie-Comeau, à Gaspé, à HavreSaint-Pierre et aux Îles-de-la-Madeleine, en complémentarité des arrêts à Québec et à Montréal (Belzile, 2008 : 23).

\section{Et demain ? Tendances}

À l'instar des autres secteurs de l'industrie, le tourisme de croisière n'est pas statique. On remarque facilement les changements qui s'opèrent quant à la taille (croissante) des navires. Les grands navires, plus rentables parce que moins coûteux à exploiter et à entretenir par passager, ont la cote chez les armateurs. Ainsi, Royal Caribbean International lançait en 2006 le Freedom of the Seas, un navire de 158000 tonnes capable de transporter 4375 passagers (le Queen Mary 2 a une capacité maximale de 3090 passagers). Les années à venir verront d'autres géants s'ajouter (voir tableau 3, Échantillon des navires de croisière, par capacité de charge). Le Genesis (annoncé par Royal Caribbean International pour 2009) promet de recevoir 5400 passagers. La taille croissante des navires entraîne d'autres changements, dont la multiplication des services. Conséquemment, alors que la croisière favorisait dans les années 1970 et 1980 le toutcompris, cette multiplication des services à bord a l'effet de valoriser la formule des suppléments (OMT, 2003 : 12). Parmi les services à la mode, les croisiéristes optent de plus en plus pour des produits associés aux soins de santé (soins corporels, spirituels, alimentaires, etc.). La croisière sans fumée (tabac interdit) connaît elle aussi sa part de popularité.

Bien que les styles décoratifs varient d'un navire à l'autre, selon que la croisière se veut jeune et dynamique ou plus réservée et classique, la structure même des navires tend à s'homogénéiser. Cherchant à reproduire l'intérieur des hôtels européens prestigieux, les architectes continuent de doter les navires de grands atriums (ill. 4). Les plus grands navires favorisent l'atrium horizontal au contraire des plus petits où il est développé en hauteur. Jeux de miroirs et d'éclairage en plus, le décor qui en résulte s'apparente à celui des centres commerciaux ou casinos nord-américains les plus imposants et cherche à créer une atmosphère de fête continue.

Des navires de plus grande capacité rendent possible l'ajout de nouvelles infrastructures de divertissement. Ils permettent aussi de tenir compte des voyageurs handicapés ou à mobilité réduite avec davantage de cabines adaptées à leurs besoins (ameublement et architecture compatibles avec le fauteuil roulant et service d'aide).

Si la taille croissante des navires permet d'accroître leur capacité de charge, celle-ci se fait

\section{Tableau 6}

Nombre de croisiéristes au Canada, par port (2003)

\begin{tabular}{ccc} 
& $\begin{array}{c}\text { Nombre de } \\
\text { croisiéristes }\end{array}$ & $\begin{array}{c}\text { Part de } \\
\text { marché }\end{array}$ \\
\hline Vancouver & 936233 & $60,3 \%$ \\
Victoria & 185978 & $12,0 \%$ \\
Halifax & 170425 & $11,0 \%$ \\
Saint John & 83300 & $5,4 \%$ \\
Québec & 59568 & $3,8 \%$ \\
Montréal & 33427 & $2,2 \%$ \\
Autres ports & 84358 & $5,4 \%$ \\
\hline TOTAL & 1553289 & $100 \%$ \\
\hline
\end{tabular}

Source : BREA (2004 : 23, cité dans Legendre, 2006).

au détriment des espaces. Ainsi, les cabines des années 2000 sont plus petites. Elles sont aussi de plus en plus nombreuses à offrir une vue sur l'intérieur du navire plutôt que sur la mer. En revanche, la densité de visiteurs sur le navire force les architectes à repenser l'espace, avec de plus en plus de balcons et de ponts privés pour les cabines supérieures. La taille accrue des navires nécessite aussi le réaménagement des installations portuaires. Pour pallier ces difficultés, plusieurs voyagistes commencent à construire et à gérer leurs propres terminaux (Ward, 2007 : 12), comme ils ont appris à le faire avec les espaces ludiques (plages, notamment).

Bien que les armateurs et les voyagistes soient portés à multiplier les efforts pour lancer des navires de grande capacité, le temps des navires de croisière plus modestes (moins de 500 passagers) n'est pas encore révolu. Certains croisiéristes choisissent délibérément de restreindre la diversité des services offerts à bord pour voyager sur un navire de plus petite taille, favorisant une atmosphère plus intimiste et modérée.

La durée des croisières (en moyenne huit jours) connaît elle aussi des variations, aux deux extrêmes du créneau. D'une part, la demande pour des croisières de longue durée (plus de huit jours à plusieurs semaines, voire un ou deux mois) est en hausse. Ces croisières prennent souvent la forme de tours autour du monde (une vingtaine 
de navires offrent le produit en 2008). Par ailleurs, les croisières de plus courte durée (moins de huit jours) connaissent aussi un gain de popularité auprès d'une clientèle disposant de moins de temps ou souhaitant s'initier au produit. Enfin, les croisières spécialisées, notamment dans les régions polaires, constituent un véritable phénomène à l'intérieur du phénomène.

Édifiée pendant les années 1920 et 1930 avant d'être condamnée à la fin des années 1950, l'industrie de la croisière a constamment su s'adapter aux changements politiques ainsi qu'à ceux imposés par la conjoncture socioéconomique. En ce début de millénaire, la croisière, en plein effervescence, demeure dépendante de facteurs extérieurs, tant sociaux et économiques que politiques. En dépit des instabilités et des changements du monde dans lequel il évolue, le navire, et encore plus la croisière, continuent de fasciner et d'appeler vers une expérience qui, au-delà des mers, demeure celle d'infrastructures hors du commun, intimement liées aux percées technologiques et à l'imaginaire humain.

Alain A. Grenier est professeur au Département d'études urbaines et touristiques de l'Université du Québec à Montréal.

\section{Notes}

1 Pour une liste complète des articles publiés sur ce secteur, voir Réseau international de recherche en tourisme polaire polaire [www. polartourismnetwork.uqam.ca].

\section{Bibliographie}

Belzile, François (2008), Stratégie de développement durable et de promotion des croisières internationales sur le fleuve St-Laurent, Ministère du Tourisme, Québec.

Bourdieu, Pierre (1979), La distinction - critique sociale du jugement, Paris, Éditions de Minuit.

BREA (Business Research and Economic Advisors) (2004), The Contribution of the International Cruise Industry to the Canadian Economy in 2003, Rapport préparé pour la North West Cruiseship Association, Vancouver Port Authority et la St. Lawrence Cruise Association.

BREA (Business Research \& Economic Advisors) (2007), The Contribution of the North American Cruise Industry to the U.S. Economy in 2006, Rapport préparé pour la Cruise Line International Association, Exton, [http:// www.cruising.org/Press/research/U.S.CLIA. Economic.Study.2006.pdf], consulté le 31 mars 2008.
Carnival (2005), Carnival Expected To Carry Record 500,000 Kids in 2004, [www.carnival.com/ CMS/Articles/kidsvirtual.aspx], consulté le 31 mars 2008.

Cartwright, Roger et Carolyn Baird (1999), The Development and Growth of the Cruise Industry, Oxford, Butterworth/Heinemann.

CIN (Cruise Industry News) (2008), "Growth Curve ", Cruise Industry News, [http://tinyurl. com/6fpeb9], consulté le 3 mars 2008.

CLIA (Cruise Lines International Association) (2006), "Cruise Industry Overview - Marketing Edition 2006 ", Cruise Lines International Association, Press Room Research, [http://www.cruising. org/press/overview\%202006/2.cfm], consulté le 11 mars 2008

Cudahy, Brian J. (2001), The Cruise Ship Phenomenon in North America, New York, Cornell Maritime Press.

Dickinson, Bob et Andy Vladimir (1996 [2007]), Selling the Sea - An Inside Look at the Cruise Tourism Industry, Wiley \& Sons, New York.

Douglas, Ngaire et Norman Douglas (1996), «P\&O's Pacific ", dans A. Pizman et Y. Mansfield (dir.), Consumer Behaviour in Tourism and Travel, Londres, Haworth \& Haworth, p. 369-392.

Douglas, Ngaire et Norman Douglas (1999), « Cruise Passenger Behaviour: A Comparative Study ", Journal of Tourism Studies, vol. $7, n^{\circ} 2$.

Dwyer, Larry et Peter Forsyth, "Economic Significance of Cruise Tourism», Annals of Tourism Research, 1998, vol. 25, n² 2, p. 393415.

Ebersold, Wiliam B. (2004), " Cruise Industry in Figures ", Business Briefing - Global Cruise 2004, Washington, US Department of Transport, [http://www.touchbriefings.com/ pdf/858/ACF7B5.pdf], consulté le 2 juin 2008.

Gamache, C. (2005), "Retombées de l'industrie des croisières au Québec ", Bulletin économique du transport, $n^{\circ} 35$, p. 12-23.

Gibson, Philip (2006), Cruise Operations Management, Amsterdam, Elsevier.

Graburn, Nelson (2001), "Secular Ritual: A General Theory of Tourism ", dans, V. Smith et M. Brent (dir.), Hosts and Guests Revisited: Tourism Issues of the $21^{\text {st }}$ Century. New York. Cognizant Communication, p. 42-52.

Grenier, Alain A. (2003), Croisières et tourisme polaire dans le Passage du Nord-Est, Publication des sciences sociales, Rovaniemi, Finlande, Université de Laponie.

Grenier, Alain A. (2004), The Nature of Nature Tourism, Publication of the Social Sciences, Rovaniemi, Finland, University of Lapland.

Jaakson, Reiner (2004), "Beyond the Tourist Bubble? Cruiseship Passengers While in Port ", Annals of Tourism Research, vol. 31, $n^{\circ} 1$, p. 44-60.

Jabour, Julia (2007), « Underneath the Radar: Emergency Search and Rescue Insurance for East Antarctic Tourism ", Tourism in Marine Environments, vol. 4, nos 2-3, p. 203-220.

Jafari, Jafar (1988), " Le système du touriste : modèles socio-culturels en vue d'applications théoriques et pratiques ", Loisir et Société, vol. $11, n^{\circ} 1$, p. 59-80.

Legendre, Élise (2006), Industrie de la croisière Tendances et débouchés pour les exportateurs canadiens 2005, Agriculture et agroalimentaire Canada, [http://www.ats.agr.gc.ca/us/4120_f. htm\#11], consulté le 4 avril 2008.
Lois, P., J. Wang, A. Wall et T. Ruxton (2004), "Formal Safety Assessment of Cruise Ships ", Tourism Management, vol. 25, p. 93-109.

Lutgens, Frederick (1992), Essentials of Geology, New York, MacMillian.

Mancini, Marc (2004), Cruising: A Guide to the Cruise Line Industry, New York, ThomsonDelmar Learning.

Moskwa, Wojciech (2007), "Royal Caribbean Orders \$1.2 Bln Cruise Giant ", Reuters UK, 3 avril 2007, [http://tinyurl.com/6ktqzd], consulté le 4 avril 2008.

OMT (Organisation mondiale du tourisme) (2003), L'activité des croisières dans le monde, Madrid.

Organisation for Economic Co-Operation and Development (OECD/OCDE) (1970), Trends in the Transport Sector 1957-1970, (UK) Maritime Transport.

Petrick, James F. (2004) « Segmenting Cruise Passengers with Price Sensitivity ", Tourism Management, vol. 26, n० 5, p. 753-762.

Petrick, James, F, Xiang Robert Li et Sun-Young Park (2007), " Cruise Passengers' DecisionMaking Processes ", Journal of Travel \& Tourism Marketing, vol. 23, no 1, p. 1-14.

Ritter, W. et C. Schaffer (1998). "Cruise Tourism: A Chance of Sustainability ", Tourism Recreation Research, vol. 10, n², p. 164-188.

Swinford, Steven (2007), "BA Sat Corpse in First Class ", Times online (Sunday Times), 18 mars, [http://www.timesonline.co.uk/tol/ news/uk/article1530572.ece], consulté le 25 mars 2008.

Teye, Victor B. et Denis Leclerc (1998), "Product and Service Delivery Satisfaction Among North American Cruise Passengers ", Tourism Management, vol. 19, no 2, p. 153-160.

Wang, Ning (2000), Tourism and Modernity - A Sociological Analysis, Londres, ElsevierPergamon.

Ward, Douglas (2001), Complete Guide to Cruising \& Cruise Ships 2002, Londres, Berlitz Publishing.

Ward, Douglas (2007), Complete Guide to Cruising \& Cruise Ships 2008, Londres, Berlitz Publishing.

Weaver, Adam (2005), "The McDonaldization Thesis and Cruise Tourism ", Annals of Tourism Research, vol. 23, n², p. 346-366.

Wiklund, K.M. (2008), "Marine Safety and Risk Awareness ", IAATO Antarctic Tourism Conference, Miami, 18 mars 2008.

Wilkinson, P. (1999), «Caribbean Cruise Tourism: Delusion? Illusion? ", Tourism Geographies, vol. 1, p. 261-282.

Wood, Robert E. (2000). "Caribbean Cruise Tourism. Globalization at Sea ", Annals of Tourism Research, vol. 27, n² 2, p. 345-370.

Yarnal, Careen M. (2004), "Missing the Boat? A Playfully Serious Look at Group Cruise Tour Experience ", Leisure Sciences, vol. 21, no 3, p. 349-372.

Yarnal, Careen M. et Deborah Kersterrer (2005), " Casting Off - An Exploratorion of Cruise Ship Space, Group Tour Behaviour, and Social Interaction ", Journal of Travel Research, vol. 43, p. 368-379.

YLE - Yleisradio Oy (2007), " Worker Shortage Threatens Shipbuilding Industry ", YLE News, [http://www.yle.fi/news/left/id57172.html], consulté le 3 avril 2007. 